\title{
Enzyme therapy and immune response in relation to CRIM status: the Dutch experience in classic infantile Pompe disease
}

\author{
Carin M. van Gelder • Marianne Hoogeveen-Westerveld • Marian A. Kroos • \\ Iris Plug • Ans T. van der Ploeg • Arnold J. J. Reuser
}

Received: 15 November 2013 /Revised: 30 January 2014 / Accepted: 12 March 2014 / Published online: 9 April 2014

(C) The Author(s) 2014. This article is published with open access at Springerlink.com

\begin{abstract}
Background Enzyme-replacement therapy (ERT) in Pompe disease - an inherited metabolic disorder caused by acid $\alpha$ glucosidase deficiency and characterized in infants by generalized muscle weakness and cardiomyopathy - can be complicated by immune responses. Infants that do not produce any endogenous acid $\alpha$-glucosidase, so-called CRIM-negative patients, reportedly develop a strong response. We report the clinical outcome of our Dutch infants in relation to their CRIM status and immune response.
\end{abstract}

Communicated by: Stephanie Gruenewald

Electronic supplementary material The online version of this article (doi:10.1007/s10545-014-9707-6) contains supplementary material, which is available to authorized users.

C. M. van Gelder • I. Plug • A. T. van der Ploeg

Department of Pediatrics, Division of Metabolic Diseases and Genetics, Center for Lysosomal and Metabolic Diseases, Erasmus MC University Medical Center, Rotterdam, The Netherlands

C. M. van Gelder

e-mail: carinvangelder@gmail.com

I. Plug

e-mail: i.plug@erasmusmc.nl

A. T. van der Ploeg

e-mail: a.vanderploeg@erasmusmc.nl

M. Hoogeveen-Westerveld • M. A. Kroos • A. J. J. Reuser $(\square)$ Department of Clinical Genetics, Center for Lysosomal and Metabolic Diseases, Erasmus MC University Medical Center, Dr Molewaterplein 50, 3015 GE Rotterdam, The Netherlands e-mail: a.reuser@erasmusmc.nl

M. Hoogeveen-Westerveld

e-mail: m.hoogeveen-westerveld@erasmusmc.nl

M. A. Kroos

e-mail: m.a.kroos@erasmusmc.nl
Methods Eleven patients were genotyped and their CRIM status was determined. Antibody formation and clinical outcome were assessed for a minimum of 4 years.

Results ERT was commenced between 0.1 and 8.3 months of age, and patients were treated from 0.3 to 13.7 years. All patients developed antibodies. Those with a high antibody titer (above 1:31,250) had a poor response. The antibody titers varied substantially between patients and did not strictly correlate with the patients' CRIM status. Patients who started ERT beyond 2 months of age tended to develop higher titers than those who started earlier. All three CRIM-negative patients in our study succumbed by the age of 4 years seemingly unrelated to the height of their antibody titer.

Conclusion Antibody formation is a common response to ERT in classic infantile Pompe disease and counteracts the effect of treatment. The counteracting effect seems determined by the antibody:enzyme molecular stoichiometry. The immune response may be minimized by early start of ERT and by immune modulation, as proposed by colleagues. The CRIM-negative status itself seems associated with poor outcome.

$\begin{array}{ll}\text { Abbreviations } \\ \text { ERT } & \text { enzyme-replacement therapy } \\ \text { CRIM } & \text { cross reactive immunological material } \\ \text { LSDs } & \text { lysosomal storage disorders } \\ \text { MPS } & \text { mucopolysaccharidoses } \\ \text { GAA } & \text { acid } \alpha \text {-glucosidase gene } \\ \text { LVMI } & \text { left ventricular mass index } \\ \text { FCS } & \text { fetal calf serum } \\ \text { PBS } & \text { phosphate-buffered saline } \\ \text { MUGlc } & \text { 4-methylumbelliferyl- } \alpha \text {-D-glucopyranoside } \\ \text { ELISA } & \text { enzyme-linked immunosorbent assay } \\ \text { BSA } & \text { bovine serum albumin } \\ \text { AIMS } & \text { Alberta Infant Motor Scale } \\ \text { IAR } & \text { infusion-associated reaction. }\end{array}$




\section{Introduction}

Immune responses are common in lysosomal storage disorders (LSDs) in which enzyme-replacement therapy (ERT) is applied (Brooks et al 2003; Wang et al 2008). The aim of ERT is to correct the enzyme deficiencies in LSDs by intravenous infusion of recombinant human enzymes. ERT is now available for Gaucher disease, Fabry disease, the mucopolysaccharidoses (MPS I, II and VI), and for Pompe disease. Immune responses have been seen in all these diseases (Brooks et al 2003; Wang et al 2008).

Pompe disease (glycogen storage disease type II, acid maltase deficiency, OMIM \# 232300) is a lysosomal storage disorder caused by mutations in the acid $\alpha$-glucosidase gene ( $G A A$, EC 3.2.1.20) (Hirschhorn and Reuser 2001; van der Ploeg and Reuser 2008). The disease is autosomal recessive and has a broad clinical spectrum (Güngör and Reuser 2013). At the severe end of the spectrum, patients with classic infantile Pompe disease present with muscle weakness, hypertrophic cardiomyopathy and respiratory insufficiency in the first few months of life. If untreated, they usually succumb to cardiorespiratory insufficiency before the end of their first year (van den Hout et al 2003; Kishnani et al 2006a). Their rapid demise is caused by a virtually total deficiency of acid $\alpha$-glucosidase activity. Treatment with alglucosidase alfa reverses the cardiomyopathy, improves motor function, and extends the survival of patients with classic infantile Pompe disease (Van den Hout et al 2000, van den Hout et al 2004; Klinge et al 2005a; Klinge et al 2005b; Kishnani et al 2006b, 2007; Nicolino et al 2009; Kishnani et al 2009; Chakrapani et al 2010).

Over $95 \%$ of affected infants receiving ERT develop antibodies to alglucosidase alfa (Kishnani et al 2010). In classic infantile Pompe disease, a distinction is often made between CRIM-negative patients (cross reactive immunological material) who lack any form of endogenous acid $\alpha$ glucosidase and CRIM-positive patients who synthesize some catalytically inactive acid $\alpha$-glucosidase. High and sustained antibody titers were reported to occur mainly in CRIMnegative patients and to be associated with a poor clinical outcome (Kishnani et al 2010; Banugaria et al 2011). Here we report on the immune response to ERT in 11 patients with classic infantile Pompe disease who were treated for up to 13 years. We examined 1.) the relationship between antibody formation and the patients' CRIM status and 2.) the impact of antibody formation on the patients' clinical outcome.

\section{Materials and methods}

Patients

We describe 11 patients with classic infantile Pompe disease who received ERT in our hospital between 1999 and 2012.
Classic infantile Pompe disease was defined as symptoms of muscle weakness within 6 months after birth; hypertrophic cardiomyopathy (left ventricular mass index (LVMI) $>+2 \mathrm{SD}$ $\left(>75 \mathrm{~g} / \mathrm{m}^{2}\right)$ (Poutanen and Jokinen 2007)); less than $1 \%$ acid $\alpha$-glucosidase activity in fibroblasts; and severe mutations in both $G A A$ alleles. Activity assays and mutation analysis were performed as described previously (Kroos et al 1997, 2007). All patients participated in consecutive trials investigating the safety and efficacy of ERT (20 mg/kg every other week to $40 \mathrm{mg} / \mathrm{kg}$ weekly). Initially, four patients received recombinant human $\alpha$-glucosidase from the milk of transgenic rabbits (Van den Hout et al 2000). From 2004 onward, all patients were treated with alglucosidase alfa. The Institutional Review Board approved all studies and the parents of all patients gave written informed consent.

\section{CRIM status}

Two methods were used to determine the patients' CRIM status. Cultured skin fibroblasts from the patients were used in the first method. They were grown in Dulbecco's modified Eagle's medium (DMEM) supplemented with $10 \%$ fetal calf serum (FCS) and antibiotics, and were harvested with trypsin 1 week after reaching confluence. Frozen cell pellets were lysed in $10 \mathrm{mM}$ phosphate-buffered saline (PBS) $\mathrm{pH} 7.0$ containing $1 \%$ Triton-X100 and protease inhibitors. A $10 \mu \mathrm{L}$ aliquot containing $100 \mu \mathrm{g}$ protein was mixed with $10 \mu \mathrm{L}$ sample buffer (NuPAGE, LDS sample buffer, Life Technology, with $4 \%$ SDS instead of $0.84 \%$ ) and applied to SDS-PAGE (Bio-Rad Criterion XT 4-12\% MOPS gel system). After blotting onto nitrocellulose the various molecular forms of acid $\alpha$-glucosidase were visualized with polyclonal rabbit antibodies against recombinant-human acid $\alpha$-glucosidase and goat anti-rabbit IRDye 680LT as secondary antibody using an Odyssey infrared imager (LI-COR Biosciences).

The second method for determining the CRIM status was based on transient expression of GAA cDNA constructs containing the patients' pathogenic mutations in HEK293T cells (one mutation per construct). The activity of acid $\alpha$-glucosidase in these cells and in the culture medium was measured with the artificial substrate 4-methylumbelliferyl- $\alpha$-D-glucopyranoside (MUGlc, Sigma) at $72 \mathrm{~h}$ after transfection. The biosynthetic forms of acid $\alpha$-glucosidase were separated by SDS-PAGE and visualized by immunoblotting (Hermans et al 1998).

Antibody detection

Blood samples for antibody titer measurements were drawn before the start of ERT and every 3 months thereafter just before the start of enzyme infusion. The sera were stored at $-20^{\circ} \mathrm{C}$. An enzyme-linked immunosorbent assay (ELISA) was used to determine the titers. To this end a 96-well plate (Nunc, F96 Maxisorp, Denmark) was coated with $50 \mu \mathrm{L} /$ well 
alglucosidase alfa in a concentration of $5 \mu \mathrm{g} / \mathrm{mL}$, diluted in PBS ( $\mathrm{pH} \mathrm{7.4),} \mathrm{and} \mathrm{incubated} \mathrm{for} 2 \mathrm{~h}$ at room temperature under continuous shaking. Plates were blocked overnight at $4^{\circ} \mathrm{C}$ with a solution of bovine serum albumin (BSA; Sigma A7030) in PBS ( $1 \%$ weight/volume). The plates were rinsed six times at room temperature with $200 \mu \mathrm{L}$ washing buffer (0.05\% Tween-20 in PBS). Plates were then incubated with $50 \mu \mathrm{L}$ of five-fold serial dilutions of patients' sera for $1 \mathrm{~h}$ during shaking. Samples were diluted from 50 to $3,906,250$ fold in dilution buffer (BSA/PBS containing $0.05 \%$ Tween20). Sera from healthy individuals were used as negative controls, and rabbit antiserum against alglucosidase alfa as a positive control. After washing of the plates, $50 \mu \mathrm{L}$ conjugate was added to each well: polyclonal goat-anti-human-[IgG, $\operatorname{IgA}$ and $\operatorname{IgM}]-H R P$ (Acris) in a 20,000-fold dilution for human sera, and goat-anti-rabbit-IgG-HRP (Sigma) in a 10,000-fold dilution for rabbit serum. After $1 \mathrm{~h}$ incubation at room temperature followed by thorough washing, $100 \mu \mathrm{L}$ Tetramethylbenzidine Microwell Peroxidase substrate (Kirkegaard and Perry Laboratories, Maryland) was added, and the plates were incubated for $10 \mathrm{~min}$. The colorimetric reaction was stopped by the addition of $100 \mu \mathrm{L} 1 \mathrm{M}$ phosphoric acid $\left(\mathrm{H}_{3} \mathrm{PO}_{4}\right)$. Absorbance was measured at $450 \mathrm{~nm}$ with a spectrophotometer (Thermo Electron Corporation, Vantaa, Finland). The maximal dilution at which absorbance was at least twice that of the negative control was taken as titer.

An antibody titer assay based on immunoprecipitation of alglucosidase alfa was used as second semi-quantitative method (de Vries et al 2010).

\section{Inhibition of alglucosidase alfa uptake}

Fibroblasts from a patient homozygous for the 525delT mutation fully deficient in acid $\alpha$-glucosidase production were seeded in 24-well tissue-culture plates and maintained at $37^{\circ} \mathrm{C}$ in Ham's F10 medium supplemented with $10 \%$ FCS and antibiotics. To measure the uptake of alglucosidase alfa, we added Pipes to the medium in a final concentration of $3 \mathrm{mM}$ to make the medium slightly acidic ( $\mathrm{pH} 6.8$ ). The enzyme was added in an amount equivalent to $200 \mathrm{nmol} \mathrm{MUGlc/h}$ per $200 \mu \mathrm{L}$ medium. Finally, $20 \mu \mathrm{L}$ of the patients' sera were added. The acid $\alpha$-glucosidase activity in the medium was measured directly after enzyme addition and prior to cell harvest. Uptake of alglucosidase alfa was measured in cell homogenates. MUGlc was used as substrate.

\section{Clinical assessments}

The clinical outcome was evaluated by analyzing survival, ventilator use, gross motor function, and cardiac dimensions at baseline and at regular intervals; the latter by 2D-guided Mmode echocardiography. The LVMI was calculated as a measure for hypertrophic cardiomyopathy. Motor development was assessed using the Alberta Infant Motor Scale (AIMS) (Piper and Darrah 1994).

Safety assessments included the monitoring of infusionassociated reactions (IARs). All adverse events that were judged to be possibly, probably or definitely related to ERT were considered IARs.

Statistical analysis

Due to limitations in patient numbers, the clinical data was summarized using descriptive statistics. All patients were followed-up for at least 4 years after the start of ERT, or until death. Data were analyzed using SPSS for Windows version 20, SPSS Inc., Chicago, IL.

\section{Results}

Patients

This study describes 11 patients (five boys and six girls) with classic infantile Pompe disease (Table 1). All had symptoms before the age of 3.5 months; nine started ERT before the age of 4 months. Two patients started ERT at the ages of 7 and 8 months when they were severely affected. All 11 patients had cardiac hypertrophy, less than $1 \%$ of average normal acid $\alpha$-glucosidase activity in cultured fibroblasts, and a severe mutation in both $G A A$ alleles (Table 1). They were treated with ERT for 0.3 to 13.7 years (median duration 5.6 years).

\section{CRIM status}

'CRIM status' in this study is defined as the ability to detect any acid $\alpha$-glucosidase with immunological methods in either the patients' cultured fibroblasts or in HEK293 cells in which mutated GAA constructs with the patients' mutations were expressed. A CRIM-positive status indicates that molecular forms of acid $\alpha$-glucosidase could be detected. A CRIMnegative status indicates that these were undetectable.

Figure 1 presents an example of the first type of analysis in fibroblasts. Cell homogenates were analyzed by SDS-PAGE followed by immunoblotting. Compared to normal synthesis of acid $\alpha$-glucosidase in fibroblasts of a healthy individual $(\mathrm{Wt})$, represented by the presence of a $110 \mathrm{kD}$ precursor and molecular species of 95,76 and $70 \mathrm{kD}$, fully maturated enzyme of $76 \mathrm{kD}$ was not detected in cells from any of the patients. However, the $110 \mathrm{kD}$ precursor was detected in eight cases. In four of these cases (pts 1, 3, 10, and 11), the apparent molecular mass of the precursor was near normal. In the other four cases (pts 2, 5, 6, and 9), the mass was abnormally low due to either homozygosity or heterozygosity for the rather common exon 18 deletion (c.2481+102_2646+31del). Proteolytic conversion of the $110 \mathrm{kD}$ precursor to the $95 \mathrm{kD}$ 
Table 1 Baseline characteristics

\begin{tabular}{|c|c|c|c|c|c|c|c|}
\hline $\mathrm{Pt}$ & Gender & Ethnic origin & Age (months) & Resp. function & AIMS score & LVMI in SD & Genotype \\
\hline 1 & M & Turkish & 0.1 & OS & $\mathrm{N}$ & +5 & $\begin{array}{l}\text { c. } 1460 \mathrm{~T}>\mathrm{C} \\
\text { c. } 1460 \mathrm{~T}>\mathrm{C}\end{array}$ \\
\hline 2 & $\mathrm{~F}$ & Caucasian & 0.5 & OS & $\mathrm{N}$ & +22 & $\begin{array}{l}\text { c. } 2481+102 \_2646+31 \mathrm{del} \\
\text { c. } 2481+102 \_2646+31 \mathrm{del}\end{array}$ \\
\hline 3 & M & Caucasian & 1.2 & NS & $\mathrm{A}$ & +15 & $\begin{array}{l}\text { c. } 1933 \mathrm{G}>\mathrm{T} \\
\text { c. } 525 \mathrm{delT}\end{array}$ \\
\hline 4 & M & Turkish & 1.9 & NS & $\mathrm{N}$ & +30 & $\begin{array}{l}\text { c. } 2741 \text { delinsCAG } \\
\text { c.2741delinsCAG }\end{array}$ \\
\hline 5 & M & Caucasian & 2.2 & NS & $\mathrm{N}$ & +10 & $\begin{array}{l}\text { c. } 2481+102 \_2646+31 \mathrm{del} \\
\text { c. } 525 \mathrm{delT}\end{array}$ \\
\hline 6 & $\mathrm{~F}$ & Caucasian & 2.4 & NS & A & +23 & $\begin{array}{l}\text { c. } 2481+102 \_2646+31 \mathrm{del} \\
\text { c. } 2481+102 \_2646+31 \mathrm{del}\end{array}$ \\
\hline $7^{\mathrm{a}}$ & $\mathrm{F}$ & Caucasian & 3.0 & NS & A & +31 & $\begin{array}{l}\text { c. } 525 \mathrm{delT} \\
\text { c. } 525 \mathrm{delT}\end{array}$ \\
\hline 8 & $\mathrm{~F}$ & Caucasian & 3.6 & OS & A & +24 & $\begin{array}{l}\text { c. } 378 \_379 \mathrm{del} \\
\text { c. } 525 \mathrm{delT}\end{array}$ \\
\hline $9^{\mathrm{a}}$ & M & Caucasian & 3.8 & NS & $\mathrm{N}$ & +14 & $\begin{array}{l}\text { c. } 2481+102 \_2646+31 \mathrm{del} \\
\text { c. } 1799 \mathrm{G}>\mathrm{A}\end{array}$ \\
\hline $10^{\mathrm{a}}$ & $\mathrm{F}$ & Caucasian & 7.2 & IV & $A^{b}$ & +18 & $\begin{array}{l}\text { c. } 1115 \mathrm{~A}>\mathrm{T} \\
\text { c. } 525 \mathrm{delT}\end{array}$ \\
\hline $11^{\mathrm{a}}$ & $\mathrm{F}$ & Caucasian & 8.3 & OS & $\mathrm{A}^{\mathrm{b}}$ & +68 & $\begin{array}{l}\text { c. } 1913 \mathrm{G}>\mathrm{T} \\
\text { c. } 1548 \mathrm{G}>\mathrm{A}\end{array}$ \\
\hline & Male $45 \%$ & Caucasian $81 \%$ & Median 3.0 & Ventilated $9 \%$ & & Median +22 & \\
\hline
\end{tabular}

Pt patient, $M$ male, $F$ female, Resp respiratory, $O S$ oxygen via nasal cannula, $N S$ no respiratory support, $I V$ invasive ventilation, $N$ within normal range of healthy peers, $A$ atypical motor development (AIMS score $\leq-2 \mathrm{SD}$ ), LVMI left ventricular mass index, $S D$ standard deviation

${ }^{a}$ These patients initially received recombinant human acid $\alpha$-glucosidase from transgenic rabbits

${ }^{\mathrm{b}}$ Paresis arms and paralysis legs

intermediate could be demonstrated only in cells of patient 9 . Three patients did not have any trace of acid $\alpha$-glucosidase due to either homozygosity for c.525delT (pt 7) or c.2741delinsCAG (pt 4), or to compound heterozygosity for c.525delT and c.378_379del (pt 8). Based on the outcome of this analysis, eight of the 11 patients were designated CRIMpositive and three CRIM-negative.

As an alternative approach determining the patients' CRIM status, we introduced the mutations in a GAA cDNA expression construct and studied their isolated effect on acid $\alpha$ glucosidase synthesis and maturation in HEK293T cells (Fig. 2). Transient expression of the five missense mutations identified among the patients in this study revealed synthesis of the $110 \mathrm{kD}$ acid $\alpha$-glucosidase precursor with either normal (c.1933G $>$ T, c.1913G $>$ T, and c.1115A $>$ T) or slightly higher than normal (c.1460 T $>$ C and c. $1799 \mathrm{G}>\mathrm{A}$ ) molecular mass. The c.1799G $>$ A and c.1460 $\mathrm{T}>\mathrm{C}$ encoded precursors were also clearly present in the culture medium, but the c.1933G $>$ T, c.1913G $>$ T, and c.1115A $>$ T encoded precursors were not
(Fig. 2; medium). Figures 1 and 2 both illustrate that the conversion from $110 \mathrm{kD}$ to $95 \mathrm{kD}$ is not blocked completely in the c.1799G $>$ A construct; even the $76 \mathrm{kD}$ form was detectable.

Transient expression of c.2741delinsCAG did not reveal any acid $\alpha$-glucosidase species (Fig. 2; cells) and also this finding is consistent with the lack of acid $\alpha$-glucosidase expression in fibroblasts of the patient who is homozygous for this mutation (Fig. 1). None of the mutagenized cDNA constructs led to expression of acid $\alpha$-glucosidase activity in the transfected cells nor in the medium.

On the basis of these two types of analyses, patients 4, 7, and 8 were designated CRIM-negative; the other eight patients were designated CRIM-positive.

Antibody titers

All patients developed antibodies to alglucosidase alfa (Supplemental Fig. 1a, Table 2). Over 4 years of treatment the 
Fig. 1 Molecular forms of acid $\alpha$-glucosidase in fibroblasts. Cell homogenates were prepared as described in materials and methods. Equal amounts of protein were loaded per lane. SDS-PAGE followed by immunoblotting was used to reveal the biosynthetic forms of acid $\alpha$-glucosidase. The numbers under the lanes refer to the patient numbers. The genotypes of the patients are presented above the lanes (delexon18 or del18 stands for c.2481+102_2646+31del; p.W460X stands for c. $1548 \mathrm{G}>$ A). Wt, fibroblasts from a healthy individual; " Homozygous;

*Nonspecific background staining

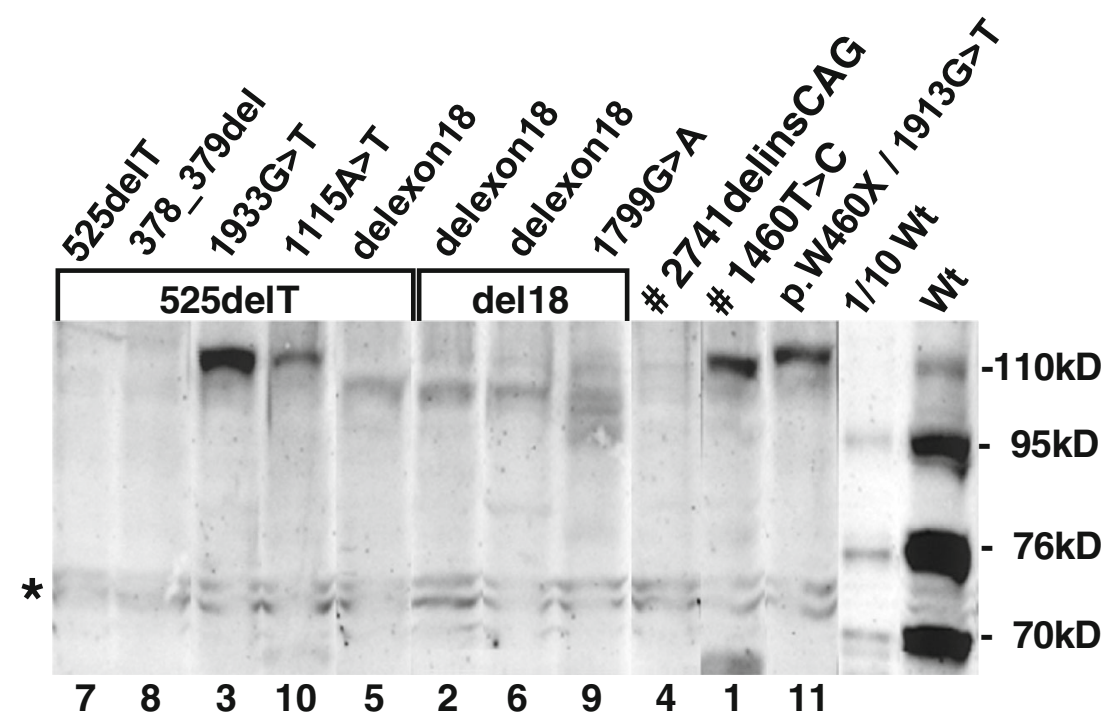

median peak antibody titer (ELISA) was 1:31,250 (range 1:1250-1:156,250). These titers were reached within 1 year of ERT. Both low and high antibody titers were measured in CRIM-positive (median 1:18,750, range 1:1250-1:156,250) and CRIM-negative patients (median 1:31,250, range 1:6250$1: 156,250)$. The peak antibody titers tended to be higher in patients who had started ERT relatively late (Table 2). Notably, none of the patients who received ERT before the age of 2 months developed titers above 1:6250.

Six patients (pts 5-8, 10 and 11) developed titers $\geq 1: 31,250$ (Table 2); titers remained high in five cases and declined temporarily to $1: 6250$ in one case (pt 10). The antibody titers of the other five patients remained $\leq 1: 6250$ over the entire study period; one of these patients was CRIM-negative and his titer eventually declined to 1:50. There was no apparent relationship between the titer and the dose of ERT, nor between the titer and the use of recombinant human acid $\alpha$ - glucosidase from either rabbit milk or $\mathrm{CHO}$ cells (results not shown).

An immunoprecipitation assay was used as an alternative method for determining the antibody titer, for which we selected three patients whose respective ELISA titers were 1:1250, 1:6250, and 1:156,250. The results are shown in Supplemental Fig. 2 and are consistent with the outcome of the ELISA assay in that both methods discriminate similarly between a low, intermediate and high titer.

\section{Inhibition of alglucosidase alfa uptake}

To measure the effect of antibodies on the uptake of alglucosidase alfa, we used sera of all patients at the time that their antibody titer was highest (Supplemental Table 1). Alglucosidase alfa and patients' sera were added together to the culture media of fibroblasts from a CRIM-negative infant.
Fig. 2 Transient expression of wildtype and mutant acid $\alpha$ glucosidase cDNA constructs. Hek293T cells were transfected with wildtype $(\mathrm{Wt})$ and mutant cDNA constructs to study abnormalities in the synthesis and post-translational modification of acid $\alpha$-glucosidase. To visualize the molecular species, the same procedure was used as in Fig. 1. *Nonspecific background staining

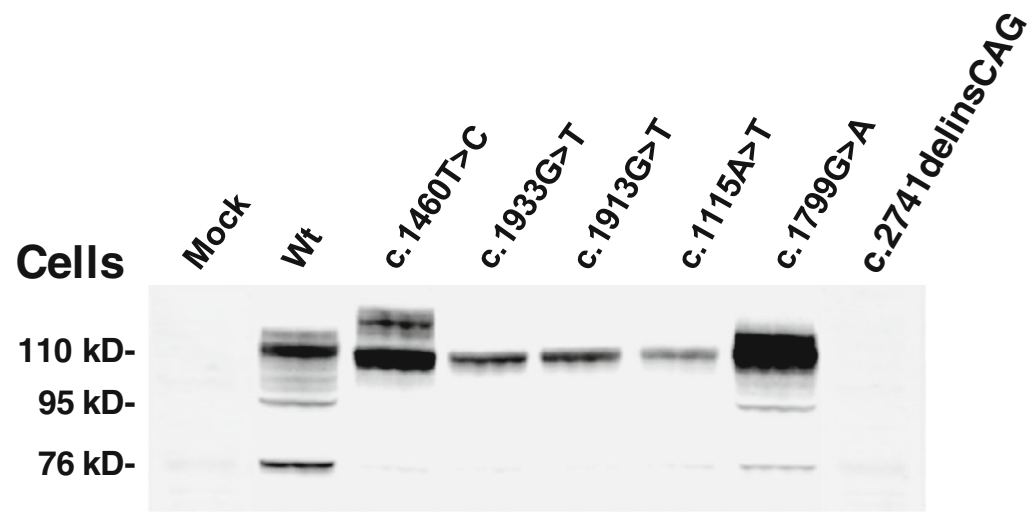

Medium

110 kD-

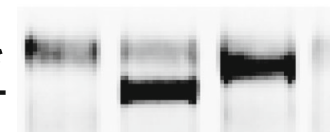

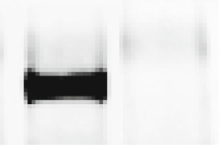


Table 2 CRIM status, antibody titer, and clinical outcome

\begin{tabular}{|c|c|c|c|c|c|c|c|c|c|c|c|c|c|}
\hline \multirow[b]{2}{*}{ Pt } & \multicolumn{2}{|l|}{ Age } & \multirow[b]{2}{*}{$\begin{array}{l}\text { CRIM } \\
\text { status }\end{array}$} & \multicolumn{4}{|l|}{ Antibody titer } & \multicolumn{6}{|c|}{ Clinical outcome at 4 years of $\mathrm{ERT}^{\mathrm{b}}$} \\
\hline & $\begin{array}{l}\text { At start of } \\
\text { ERT } \\
\text { (months) }\end{array}$ & $\begin{array}{l}\text { Current } \\
\text { (years) }\end{array}$ & & $\begin{array}{l}\text { Peak titer } \\
\text { through } 4 \\
\text { years of ERT }\end{array}$ & $\begin{array}{l}\text { Titer at } \\
4 \text { years } \\
\text { of ERT }^{\text {b }}\end{array}$ & $\begin{array}{l}\text { Last titer (y } \\
\text { start of ERT }\end{array}$ & ars after & Alive & & $\begin{array}{l}\text { asive } \\
\text { tilation }^{c}\end{array}$ & Motor status & $\begin{array}{l}\text { LVMI } \\
\text { in SD }\end{array}$ & $\begin{array}{l}\text { Dose of } \\
\text { ERT }\end{array}$ \\
\hline 1 & 0.1 & 5.6 & + & $1: 6,250$ & $1: 1,250$ & $1: 6,250$ & $(5.0)$ & $\mathrm{Y}$ & $\mathrm{Y}$ & $2.7(1: 250)$ & Sitting $^{\mathrm{e}}$ & -0.6 & $40^{\mathrm{f}}$ \\
\hline 2 & 0.5 & 8.0 & + & $1: 1,250$ & $1: 250$ & $1: 250$ & (7.1) & $\mathrm{Y}$ & $\mathrm{N}$ & & Walking & -0.7 & 20 \\
\hline 3 & 1.2 & 8.5 & + & $1: 6,250$ & $1: 1,250$ & $1: 6,250$ & $(8.0)$ & $\mathrm{Y}$ & $\mathrm{N}$ & & Walking & -1.5 & $40^{\mathrm{f}}$ \\
\hline 4 & 1.9 & $4.4^{\mathrm{a}}$ & - & $1: 6,250$ & $1: 50$ & $1: 50$ & (3.4) & $\mathrm{Y}$ & $\mathrm{Y}$ & $2.0(1: 6,250)$ & Sitting $^{\mathrm{e}}$ & +0.9 & 20 \\
\hline 5 & 2.2 & 5.2 & + & $1: 31,250$ & $1: 31,250$ & $1: 31,250$ & $(4.0)$ & $\mathrm{Y}$ & $\mathrm{N}$ & & Sitting & +1.1 & $40^{\mathrm{f}}$ \\
\hline 6 & 2.4 & 4.1 & + & $1: 31,250$ & $1: 31,250$ & $1: 31,250$ & $(3.0)$ & $\mathrm{Y}$ & $\mathrm{N}$ & & Walking & +3.7 & 40 \\
\hline 7 & 3.0 & $4.3^{\mathrm{a}}$ & - & $1: 156,250$ & $1: 156,250$ & $1: 156,250$ & (3.8) & $\mathrm{Y}$ & $\mathrm{Y}$ & $2.2(1: 31,250)$ & Sitting & +4.4 & $40^{\mathrm{f}}$ \\
\hline 8 & 3.6 & $0.6^{\mathrm{a}}$ & - & $1: 31,250$ & $1: 31,250$ & $1: 31,250$ & $(0.3)$ & $\mathrm{N}$ & $\mathrm{N}$ & & Minimal motor gain & +28.6 & 20 \\
\hline 9 & 3.8 & 14.1 & + & $1: 6,250$ & $1: 250$ & $1: 6,250$ & (12.8) & $\mathrm{Y}$ & $\mathrm{N}$ & & Walking & +0.4 & $40^{\mathrm{f}}$ \\
\hline 10 & 7.2 & 14.3 & + & $1: 31,250$ & $1: 6,250$ & $1: 156,250$ & $(12.9)$ & $\mathrm{Y}$ & $\mathrm{Y}$ & $0.6^{\mathrm{d}}$ & Tetraplegic & +4.9 & $40^{\mathrm{f}}$ \\
\hline 11 & 8.3 & 14.3 & + & $1: 156,250$ & $1: 156,250$ & $1: 156,250$ & $(11.5)$ & $\mathrm{Y}$ & $\mathrm{Y}$ & $0.9(1: 250)$ & Tetraplegic & +4.5 & $40^{\mathrm{f}}$ \\
\hline
\end{tabular}

$P t$ Patient number, ERT enzyme-replacement therapy, CRIM cross reactive immunological material, $L V M I$ left ventricular mass index, $S D$ standard deviation

${ }^{\text {a }}$ Age at death

${ }^{\mathrm{b}}$ Last available data are presented if patient did not yet receive 4 years of ERT

${ }^{\mathrm{c}}$ Age in years (antibody titer around that time)

${ }^{\mathrm{d}}$ Patient was ventilator dependent before start of ERT

${ }^{\mathrm{e}}$ Patients lost ability to walk

${ }^{\mathrm{f}}$ Dose was augmented to $40 \mathrm{mg} / \mathrm{kg} /$ week during treatment

No effects on enzyme activity or uptake of alglucosidase alfa were observed when antibody titers were $\leq 1: 6250$. Alglucosidase alfa activity in the medium was substantially inhibited (26-50\% loss of enzymatic activity) by one of three sera with a titer of $1: 31,250$ and by all three sera with a titer of $1: 156,250$. Only the three sera with the highest titer $(1: 156,250)$ resulted in inhibition $(24-42 \%)$ of alglucosidase alfa uptake.

\section{Clinical outcome over 4 years of ERT}

\section{Survival and ventilator-free survival}

One of the 11 patients was ventilator dependent before the start of ERT. Over 4 years of ERT, four more patients required invasive ventilation (at ages 0.9, 2.0, 2.2, and 2.7 years; Table 2) and three patients died (at ages 0.6, 4.3, and 4.4 years). The last antibody titers measured before the patients' deaths or respiratory insufficiency ranged from 1:50 to $1: 31,250$. The median peak antibody titer of these patients was 1:31,250 (range 1:6250-1:156,250); the median peak antibody titer of the five patients who are still alive and ventilator-free at the time of reporting was 1:6250 (range 1:1250-1:31,250). All three CRIM-negative patients died. All eight CRIM-positive patients are alive; two of them became ventilator dependent during treatment.

\section{Motor outcome}

Supplemental Fig. 1C depicts motor development over time as measured by AIMS. Over 4 years of ERT, eight patients achieved important motor milestones. Six learned to walk and two learned to sit, but three made minimal motor gains. The median peak titer of the six patients who learned to walk was 1:6250 (range 1:1250-1:31,250) against 1:31,250 (range $31,250-156,250)$ for the patients who did not learn to walk. One of the three CRIM-negative patients and five of the eight CRIM-positive patients learned to walk.

Patients 1 and 4 lost their ability to walk after developing respiratory insufficiency. Their antibody titers never rose above 1:6250. One of them was CRIM-positive, the other CRIM-negative. One other CRIM-positive patient with a peak titer of 1:31,250 temporarily lost the ability to attain a sitting position after a respiratory syncytial virus (RSV) infection at the age of 1.3 years (Supplemental Fig. 1c, pt 5). None of the patients with a longer than 4 years follow-up lost or gained motor milestones beyond 4 years of ERT.

\section{Cardiac dimensions}

At the start of ERT, all patients had hypertrophic cardiomyopathy. Over 4 years of ERT, the LVMI decreased significantly in all but one patient who died 4 months after ERT was 
initiated (Supplemental Fig. 1b). Six of the 11 patients had a normal LVMI at 4 years of ERT.

The median peak antibody titer of the patients with a normal LVMI after 4 years of ERT was 1:6250 (range $1: 1,250-31,250$ ) against $1: 31,250$ (range 1:6250-1:156,250) for those whose LVMI was increased. The LVMI remained above the reference value in all three CRIM-negative patients, against two of the eight CRIM-positive patients. Beyond 4 years of ERT, no major changes in LVMI were observed.

\section{Infusion-associated reactions}

Over 4 years of ERT, ten of the 11 patients ( $82 \%$ ) experienced one or multiple IARs. The first IARs started 0.4-24.5 months after the start of ERT and comprised the following signs and symptoms: General malaise, hypoxia, bronchospasm, dyspnea, tachycardia, bradycardia, hypotension, cyanosis, sweating, fever, vomiting, flushing, and exanthema. All IARs could be controlled by slowing the infusion rate, with or without the administration of premedication.

The only patient who did not develop IARs was CRIMpositive and had the lowest peak antibody titer over the whole period of reporting.

\section{Discussion}

Several studies have shown that antibody formation can occur in patients receiving recombinant human proteins for therapy (Wang et al 2008; Kishnani et al 2010; Banugaria et al 2011; Patel et al 2012). Our patients with classic infantile Pompe disease who were treated with alglucosidase alfa showed various immune response patterns. Low and high titers were measured in CRIM-negative and CRIM-positive patients alike. While thorough statistical analysis was prevented by the small sample size and the heterogeneity of our patient population, we noticed that patients who did not learn to walk had a relatively high titer. We also noticed that patients who had started ERT before the age of two months tended to have lower titers than those who had started later. Notably, all CRIM-positive patients were still alive at the time of reporting, whereas all CRIM-negative patients had died.

\section{GAA genotypes and CRIM status}

The quality and quantity of acid $\alpha$-glucosidase in Pompe disease depends on the GAA genotype. Ten different mutations were identified, all causing complete loss of acid $\alpha$ glucosidase activity.

The commonly used procedure to determine the CRIM status is immunoblotting and normally reveals four distinct acid $\alpha$-glucosidase species that separately and collectively are called CRIM. In healthy people (Fig. 1, Wt), the long-lived 76 and $70 \mathrm{kD}$ species comprise approximately $80 \%$ of the total CRIM. In patients, however, the synthesis of acid $\alpha$ glucosidase can be totally lost, which results in a CRIMnegative status. More often, the synthesis is derailed, and CRIM consists mainly of the $110 \mathrm{kD}$ precursor (e.g., Fig. 1, pts. 1 and 3) or a modified derivative thereof (Fig. 1, pts. 2 and 6). As it stands, the CRIM-negative status is well defined, but the CRIM-positive status encompasses a collection of qualitatively and quantitatively abnormal immunoblot profiles.

By and large, a patient's CRIM status can be predicted on the basis of its genotype (Bali et al 2012). Most non-sense mutations and frame-shift mutations lead to mRNA decay and a CRIM-negative status (e.g., 525delT in pt. 3), truncated protein species are sometimes detectable by immunoblotting (e.g., c.2481+102_2646+31del in pts. 1, 7, 10, and 11), and thus lead to a CRIM-positive status. Although the effect of missense mutations is hard to predict, they usually lead to a CRIM-positive status.

Information on the effect of missense mutations can be obtained by transient expression (Fig. 2), which is especially informative for the stage at which mutant forms of acid $\alpha$ glucosidase are degraded. For instance, the c.1460 $\mathrm{T}>\mathrm{C}$ or c. $1799 \mathrm{G}>\mathrm{A}$ encoded acid a-glucosidase precursors must have traversed the Golgi complex since they are secreted into the medium, whereas the c. $1833 \mathrm{G}>\mathrm{T}, \mathrm{c} 1913 \mathrm{G}>\mathrm{T}$ and $\mathrm{c} 1115 \mathrm{~A}>\mathrm{T}$ encoded precursors do not appear in the medium (Fig. 2) and are apparently degraded while passing through the ER/Golgi complex. By the current definition of CRIM, these five missense mutations lead to a CRIM-positive status, but obviously do not represent one and the same CRIM-positive condition.

Our application of both methods to determine the CRIM status resulted in the same outcome: eight patients are CRIMpositive and three are CRIM-negative. Notably, the patient homozygous for $\mathrm{c} .2741 \mathrm{delins} C A \mathrm{G}$ was previously designated CRIM-positive (Hermans et al 1998; Banugaria et al 2011).

\section{CRIM status and antibody titer}

Antibody formation is a natural response to foreign invading proteins. Thus, ERT is prone to evoke an immune response in CRIM-negative patients, but not necessarily in all CRIMpositive patients. Patients with Pompe disease receiving ERT respond roughly according to these principles. Analysis of the immune response in 34 treated infants showed a strong tendency toward higher and sustained antibody titers in CRIMnegative compared to CRIM-positive infants (Kishnani et al 2010). However, CRIM-positive patients can also develop high titers (Banugaria et al 2011), and CRIM-negative patients low titers (Abbott et al 2011; Al Khallaf et al 2013). Our study in 11 infants has led to similar findings. The highest peak antibody titers were measured in four of the eight CRIMpositive patients and in two of the three CRIM-negative patients. The antibody titer of the third CRIM-negative patient 
did not exceed 1:6250 and spontaneously regressed to 1:50 after 3 years of ERT. There were two CRIM-positive patients with the same $G A A$ genotype; one developed a relatively high titer, and the other a relatively low titer.

Although the number of patients in our study is small, we can firmly conclude that the CRIM status alone predicts neither the level nor the duration of the immune response. This may relate to the imprecise definition of CRIM status, which does not describe the amount, the conformation or the location of the endogenous acid $\alpha$-glucosidase. For instance, secretion of the $110 \mathrm{kD}$ precursor as opposed to intracellular degradation might reduce the immune response and contribute to the relatively low antibody titers in patients 1 and 9 . Notably, adult patients with a considerable amount of normally structured and catalytically active acid $\alpha$-glucosidase can also develop high titers (van der Ploeg et al 2010; de Vries et al 2010; Patel et al 2012; Regnery et al 2012). Altogether, we conclude that genotype and CRIM status are of limited value in predicting the height of the immune response.

As previously suggested (van Gelder et al 2012; Al Khallaf et al 2013), our study indicates that the age at start of ERT might play a role in the immune response since none of the patients who started ERT before 2 months of age developed titers $>1: 6250$. There are at least two plausible explanations for this: First, the neonatal immune system is immature, and very early administration of ERT might induce tolerance (Brooks 1999; Dierenfeld et al 2010). Second, the 'danger model' suggests that the immune system needs alarm signals from injured tissues to be activated. At a less advanced stage of disease these signals will be weaker (Matzinger 2002). Other models may equally apply.

\section{Consequences of antibody formation}

Depending on their binding sites antibodies can inhibit catalytic function, block binding to the mannose 6-phosphate receptor and prevent uptake, or otherwise misdirect the protein to macrophages and neutrophils (Brooks et al 2003; Wang et al 2008). Antibodies and antigen can also form immune complexes and trigger a cascade of adverse events (Hunley et al 2004).

In a previous case-report about an adult patient with Pompe disease we have calculated how the concentration of alglucosidase alfa specific antibodies relates to the concentration of alglucosidase alfa during enzyme infusion (de Vries et al 2010). In the present study we have applied the same arithmetic method to infants. For example, patient 11 had an ELISA titer of 1:156,250 at a certain point of treatment. At that time the corresponding titer as measured by immuneprecipitation was $40 \mathrm{nmol} \mathrm{MUGlc/h} . \mu \mathrm{L}$ (Supplemental Fig. 2) implying that $1 \mathrm{~mL}$ of the patient's serum contained enough antibodies to bind $0.13 \mathrm{mg}$ alglucosidase alfa (de Vries et al 2010). As a child receives $0.24 \mathrm{mg}$ of alglucosidase alfa per $\mathrm{mL}$ blood (based on $20 \mathrm{mg} / \mathrm{kg}$ and a circulating blood volume of $80 \mathrm{~mL} / \mathrm{kg}$ ), antibodies may bind as much as $54 \%$ of the administered enzyme. By contrast, if the titer is only $4 \mathrm{nmol} \mathrm{MUGlc} / \mathrm{h} . \mu \mathrm{L}$, corresponding with an ELISA titer of $1: 6250$, the circulating antibodies can bind only $5 \%$ of the administered aglucosidase alfa.

Although these estimates are crude they indicate that ELISA titers of 1:6250 and lower probably have no clinical significance, whereas titers of 1:31,250 and higher may counteract ERT at a dose of $20 \mathrm{mg} / \mathrm{kg}$. Accordingly, titers above 1:60,000 are expected to counteract ERT at a dose of $40 \mathrm{mg} / \mathrm{kg}$. Our arithmetic estimates of what should be considered a high titer and what should be considered a low titer remarkably correspond to the cut-off value of 1:51,200 chosen by Banaguria et al (Banugaria et al 2011).

Antibodies can impede the effect of ERT in several ways. In four cases we observed a decrease of catalytic activity suggestive for binding of antibodies to the enzyme's active site. Uptake was inhibited in three cases. In one case this was due to a combination of inactivation and uptake inhibition possibly by steric hindrance of the ligand-receptor binding. Of note, the effect of antibodies not only depends on the binding sites but also on the stoichiometry of antibodies and alglucosidase alfa in the experimental setting; changing the concentration of one of the two components can tip the balance. Whereas neutralizing antibodies were reported to be more common in CRIM-negative than in CRIM-positive patients (Kishnani et al 2010; Banugaria et al 2011), in our study their presence was not related specifically to the patients' CRIM status but to the patients' antibody titer.

It has been shown that high antibody titers in CRIMnegative as well as CRIM-positive patients are associated with shorter ventilator-free survival (Kishnani et al 2010; Banugaria et al 2011). In several adults with Pompe disease, a high titer was also accompanied by poor response to ERT (de Vries et al 2010; Patel et al 2012). Although our study group was too small and too varied to permit statistical analysis, patients with higher titers tended to attain fewer motor milestones. However, with respect to ventilator-free survival, only two of the six patients who developed respiratory insufficiency or died had a titer of $\geq 1: 31,250$ at the time that these events occurred. Two other patients had low titers, but nevertheless developed respiratory insufficiency at the age of 2 . Two patients became ventilator dependent just before or soon after the start of ERT which we ascribe to their advanced disease at the start of ERT.

\section{Conclusions and challenges}

The outcome of classic infantile Pompe patients is determined by many factors, among which are the age and disease severity at initiation of ERT, the patient's genotype, and the height of the antibody response. It is beyond question that high and 
sustained antibody titers need to be prevented in order to achieve a good response to ERT (Kishnani et al 2010; de Vries et al 2010; Banugaria et al 2011). Our study indicates that the negative effect of antibodies starts at an antibody titer of approximately 1:31,250 when the recommended dose of $20 \mathrm{mg} / \mathrm{kg}$ is used. Very early start of ERT ( $<2$ months), achievable by neonatal screening, may help to keep the antibody titers low. Recent publications indicate that immune tolerance can be successfully induced by a combination of rituximab, methotrexate, and intravenous immunoglobulins (Mendelsohn et al 2009; Messinger et al 2012; Banugaria et al 2013b), a regimen likely to be most effective when used prophylactically (Lacaná et al 2012; Banugaria et al 2013a). As the patients' genotype and related CRIM status alone are obviously not the sole determinants for the patients' immune response, identification of other triggering factors remains a challenge. Though the number of patients is very small, it occurred to us that the three CRIM-negative patients in our study had an early demise while all CRIM-positive patients survived. If the difference is not made solely by the CRIMstatus or antibody titer, might it be that CRIM-positive patients can have a tiny bit of acid $\alpha$-glucosidase activity in their tissues that we cannot detect with our current methods?

Acknowledgement The authors would like to thank all patients and their parents for participating in this study. We are grateful to L. Özkan for excellent technical assistance, to J. Hardon, R. Nelisse, and J. Koemans-Schouten for material and data collection, and to D. Alexander for correcting grammar and style. Financial support was obtained from ZonMw - Dutch organization for healthcare research and innovation of care (Grant 152001005), 'Prinses Beatrix Fonds (project number OP07-08)', and the 7th Frame Program 'EUCLYD - a European Consortium for Lysosomal Storage Diseases' of the European Union (health F2/2008 grant agreement 201678).

Conflict of interest Since August 2004, Ans van der Ploeg and Arnold Reuser have provided consulting services for Genzyme Corp., Cambridge, MA, USA, under an agreement between Genzyme Corp. and Erasmus MC, Rotterdam, the Netherlands. Erasmus MC and inventors for the method of treatment of Pompe disease by enzyme-replacement therapy receive royalty payments pursuant to Erasmus MC policy on inventions, patents and technology transfer.

Carin van Gelder, Marianne Hoogeveen-Westerveld, Marian Kroos, and Iris Plug declare that they have no conflict of interest.

Open Access This article is distributed under the terms of the Creative Commons Attribution License which permits any use, distribution, and reproduction in any medium, provided the original author(s) and the source are credited.

\section{References}

Abbott M, Prater SN, Banugaria SG et al (2011) Atypical immunologic response in a patient with CRIM-negative Pompe disease. Mol Genet Metab 104:583-586

Al Khallaf HH, Propst J, Geffrard S et al (2013) CRIM-negative Pompe disease patients with satisfactory clinical outcomes on enzyme replacement therapy. JIMD Rep 9:133-137
Bali DS, Goldstein JL, Banugaria S et al (2012) Predicting cross-reactive immunological material (CRIM) status in Pompe disease using GAA mutations: lessons learned from 10 years of clinical laboratory testing experience. Am J Med Genet C: Semin Med Genet 160:40-49

Banugaria SG, Prater SN, Ng Y-K et al (2011) The impact of antibodies on clinical outcomes in diseases treated with therapeutic protein: lessons learned from infantile Pompe disease. Genet Med 13:729-736

Banugaria SG, Prater SN, McGann JK et al (2013a) Bortezomib in the rapid reduction of high sustained antibody titers in disorders treated with therapeutic protein: lessons learned from Pompe disease. Genet Med 15:123-131

Banugaria SG, Prater SN, Patel TT et al (2013b) Algorithm for the early diagnosis and treatment of patients with cross reactive immunologic material-negative classic infantile Pompe disease: a step towards improving the efficacy of ERT. PloS One 8:e67052

Brooks DA (1999) Immune response to enzyme replacement therapy in lysosomal storage disorder patients and animal models. Mol Genet Metab 68:268-275

Brooks DA, Kakavanos R, Hopwood JJ (2003) Significance of immune response to enzyme-replacement therapy for patients with a lysosomal storage disorder. Trends Mol Med 9:450-453

Chakrapani A, Vellodi A, Robinson P et al (2010) Treatment of infantile Pompe disease with alglucosidase alpha: the UK experience. J Inherit Metab Dis 33:747-750

De Vries JM, van der Beek NAME, Kroos MA et al (2010) High antibody titer in an adult with Pompe disease affects treatment with alglucosidase alfa. Mol Genet Metab 101:338-345

Dierenfeld AD, McEntee MF, Vogler C a, et al (2010) Replacing the enzyme alpha-L-iduronidase at birth ameliorates symptoms in the brain and periphery of dogs with mucopolysaccharidosis type I. Sci Transl Med 2:60ra89.

Güngör D, Reuser AJJ (2013) How to describe the clinical spectrum in Pompe disease? Am J Med Genet A 161A:399-400

Hermans MM, Kroos MA, Smeitink JA et al (1998) Glycogen Storage Disease type II: genetic and biochemical analysis of novel mutations in infantile patients from Turkish ancestry. Hum Mutat 11:209-215

Hirschhorn R, Reuser AJJ (2001) Glycogen storage disease type II: acid alpha-glucosidase (acid maltase) deficiency. In: Scriver C, Beaudet A, Valle D, Sly W (eds) The metabolic and molecular bases of inherited disease. McGraw-Hill, New-York, pp 3389-3420

Hunley TE, Corzo D, Dudek M et al (2004) Nephrotic syndrome complicating alpha-glucosidase replacement therapy for Pompe disease. Pediatrics 114:e532-e535

Kishnani PS, Hwu W-L, Mandel H et al (2006a) A retrospective, multinational, multicenter study on the natural history of infantile-onset Pompe disease. J Pediatr 148:671-676

Kishnani PS, Nicolino M, Voit T et al (2006b) Chinese hamster ovary cell-derived recombinant human acid alpha-glucosidase in infantileonset Pompe disease. J Pediatr 149:89-97

Kishnani PS, Corzo D, Nicolino M et al (2007) Recombinant human acid $\alpha$-glucosidase: major clinical benefits in infantile-onset Pompe disease. Neurology 68:99-109

Kishnani PS, Corzo D, Leslie ND et al (2009) Early treatment with alglucosidase alpha prolongs long-term survival of infants with Pompe disease. Pediatr Res 66:329-335

Kishnani PS, Goldenberg PC, DeArmey SL et al (2010) Cross-reactive immunologic material status affects treatment outcomes in Pompe disease infants. Mol Genet Metab 99:26-33

Klinge L, Straub V, Neudorf U et al (2005a) Safety and efficacy of recombinant acid alpha-glucosidase (rhGAA) in patients with classical infantile Pompe disease: results of a phase II clinical trial. Neuromuscul Disord 15:24-31

Klinge L, Straub V, Neudorf U, Voit T (2005b) Enzyme replacement therapy in classical infantile pompe disease: results of a ten-month follow-up study. Neuropediatrics 36:6-11 
Kroos MA, Waitfield AE, Joosse M et al (1997) A novel acid alphaglucosidase mutation identified in a Pakistani family with glycogen storage disease type II. J Inherit Metab Dis 20:556-558

Kroos MA, Pomponio RJ, Hagemans ML et al (2007) Broad spectrum of Pompe disease in patients with the same c.-32-13T- $>$ G haplotype. Neurology 68:110-115

Lacaná E, Yao LP, Pariser AR, Rosenberg AMYS (2012) The role of immune tolerance induction in restoration of the efficacy of ERT in Pompe disease. Am J Med Genet C: Semin Med Genet 160:30-39

Matzinger P (2002) The danger model: a renewed sense of self. Science 296:301-305

Mendelsohn NJ, Messinger YH, Rosenberg AS, Kishnani PS (2009) Elimination of antibodies to recombinant enzyme in Pompe's disease. N Engl J Med 360:194-195

Messinger YH, Mendelsohn NJ, Rhead W et al (2012) Successful immune tolerance induction to enzyme replacement therapy in CRIMnegative infantile Pompe disease. Genet Med 14:135-142

Nicolino M, Byrne B, Wraith JE et al (2009) Clinical outcomes after longterm treatment with alglucosidase alfa in infants and children with advanced Pompe disease. Genet Med 11:210-219

Patel TT, Banugaria SG, Case LE et al (2012) The impact of antibodies in late-onset Pompe disease: A case series and literature review. Mol Genet Metab 106:301-309

Piper M, Darrah J (1994) Motor assessment of the developing infant. Saunders, Philadelphia
Poutanen T, Jokinen E (2007) Left ventricular mass in 169 healthy children and young adults assessed by three-dimensional echocardiography. Pediatr Cardiol 28:201-207

Regnery C, Kornblum C, Hanisch F et al (2012) 36 months observational clinical study of 38 adult Pompe disease patients under alglucosidase alfa enzyme replacement therapy. J Inherit Metab Dis 35:837-845

Van den Hout H, Reuser AJJ, Vulto AG et al (2000) Recombinant human alpha-glucosidase from rabbit milk in Pompe patients. Lancet 356: 397-398

Van den Hout HMP, Hop W, van Diggelen OP et al (2003) The natural course of infantile Pompe's disease: 20 original cases compared with 133 cases from the literature. Pediatrics 112:332-340

Van den Hout JMP, Kamphoven JHJ, Winkel LP et al (2004) Long-term intravenous treatment of Pompe disease with recombinant human alpha-glucosidase from milk. Pediatrics 113:e448-e457

Van der Ploeg AT, Reuser AJJ (2008) Pompe's disease. Lancet 372:13421353

Van der Ploeg AT, Clemens PR, Corzo D et al (2010) A randomized study of alglucosidase alfa in late-onset Pompe's disease. N Engl J Med 362:1396-1406

Van Gelder CM, Kroos MA, Ozkan L, et al (2012) Antibody formation to enzyme therapy in classic infantile Pompe disease: Implications of patient age. J Inherit Metab Dis 35 Suppl 1:S12.

Wang J, Lozier J, Johnson G et al (2008) Neutralizing antibodies to therapeutic enzymes: considerations for testing, prevention and treatment. Nat Biotechnol 26:901-908 